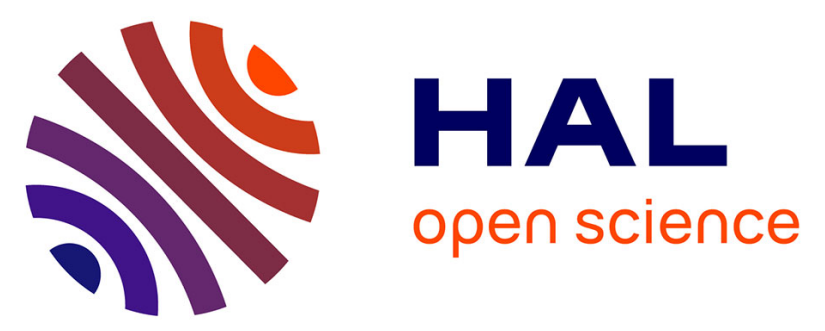

\title{
Axitinib in first-line for patients with metastatic papillary renal cell carcinoma: Results of the multicentre, open-label, single-arm, phase II AXIPAP trial
}

Sylvie Négrier, Nathalie Rioux-Leclercq, Céline Ferlay, Marine Gross-Goupil, Gwénaelle Gravis, Lionel Geoffrois, Christine Chevreau, Helen Boyle, Frédéric Rolland, Ellen Blanc, et al.

\section{- To cite this version:}

Sylvie Négrier, Nathalie Rioux-Leclercq, Céline Ferlay, Marine Gross-Goupil, Gwénaelle Gravis, et al.. Axitinib in first-line for patients with metastatic papillary renal cell carcinoma: Results of the multicentre, open-label, single-arm, phase II AXIPAP trial. European Journal of Cancer, 2020, 129, pp.107 - 116. 10.1016/j.ejca.2020.02.001 . hal-02552562

\section{HAL Id: hal-02552562 https://univ-lyon1.hal.science/hal-02552562}

Submitted on 23 Jul 2020

HAL is a multi-disciplinary open access archive for the deposit and dissemination of scientific research documents, whether they are published or not. The documents may come from teaching and research institutions in France or abroad, or from public or private research centers.
L'archive ouverte pluridisciplinaire HAL, est destinée au dépôt et à la diffusion de documents scientifiques de niveau recherche, publiés ou non, émanant des établissements d'enseignement et de recherche français ou étrangers, des laboratoires publics ou privés. 
Axitinib in first-line for patients with metastatic papillary renal cell carcinoma: results of the multicentre, open-label, single-arm phase II AXIPAP trial.

Sylvie Negrier*1, Nathalie Rioux-Leclercq ${ }^{2}$, Céline Ferlay ${ }^{3}$, Marine Gross Goupil ${ }^{4}$, Gwenaëlle Gravis ${ }^{5}$, Lionel Geoffrois ${ }^{6}$, Christine Chevreau ${ }^{7}$, Helen Boyle ${ }^{8}$, Frederic Rolland ${ }^{9}$, Ellen Blanc ${ }^{3}$, Alain Ravaud ${ }^{4}$, Slimane Dermeche ${ }^{5}$, Aude Flechon ${ }^{8}$, Laurence Albiges ${ }^{10}$, David Pérol $^{3}$ and Bernard Escudier ${ }^{10}$ for the GETUG collaborative group.

${ }^{1}$ Univ Lyon, Claude Bernard University Lyon 1, Medical Oncology, Léon Bérard cancer centre, Lyon, France

${ }^{2}$ Department of Pathology, University Hospital centre of Pontchaillou, Rennes, France ${ }^{3}$ Department of Clinical research and Innovation, Léon Bérard cancer centre, Lyon, France ${ }^{4}$ Medical Oncology, Bordeaux University Hospital, Bordeaux, France

${ }^{5}$ Medical Oncology, Paoli Calmettes Institute, Marseille, France

${ }^{6}$ Medical Oncology, Institute of cancerology of Lorraine - Alexis Vautrin, Vandoeuvre Les Nancy, France

${ }^{7}$ Medical Oncology, University institute of cancer, Toulouse- Oncopole, Toulouse, France, ${ }^{8}$ Medical Oncology, Léon Bérard cancer centre, Lyon, France

${ }^{9}$ Medical Oncology, Institute of Cancer Research in Western France, René Gauducheau cancer centre, Saint-Herblain, France

${ }^{10}$ Medical Oncology, Gustave Roussy, Villejuif, France.

Running Title: Axitinib in advanced or metastatic papillary renal cell carcinoma Corresponding author: Prof Sylvie NEGRIER, Centre Léon Bérard, 28, rue Laennec, 69373 Lyon Cedex 08, France. Fax: +33 (0)478 7827 16, Email: sylvie.negrier@lyon.unicancer.fr 
Funding: Pfizer, Centre Léon Bérard.

Centre Léon Bérard, sponsor of the study, was responsible for trial conception and coordination, data analysis, writing of the report.

Pfizer provided the study drug axitinib and funding to Centre Léon Bérard to conduct the study. Pfizer had no role in study design, data collection, data analysis, data interpretation, or writing of the report.

Keywords: advanced renal cancer, papillary renal cell carcinoma, tyrosine kinase, vascular endothelial growth factor, VEGF inhibitor, targeted therapy.

Abbreviations: PRCC: Papillary renal cell carcinoma; VEGF: vascular endothelial growth factor; VEGFr: Vascular endothelial growth factor receptor; PD1: Programmed cell death 1; PDL1: Programmed death-ligand 1; RECIST: Response Evaluation Criteria in Solid Tumors; PFS: progression free survival; OS: overall survival; RR: response rates; $24 \mathrm{w}-\mathrm{PFR}$ : progression free rate at 24 weeks; PR: partial response; SD: stable disease; PD: progression disease. 


\section{Abstract}

Introduction: Papillary renal cell carcinoma (PRCC) represents $10-15 \%$ of renal carcinomas. No standard treatments exist for metastatic PRCC (mPRCC) patients. Axitinib is indicated as second-line treatment in metastatic clear cell renal carcinoma, and we aim to assess the efficacy of this VEGF receptor inhibitor in front line for metastatic PRCC.

Methods: This French multicenter phase II study AXIPAP enrolled untreated metastatic PRCC patients, with measurable disease, ECOG PS $\leq 1$, and adequate organ functions. PRCC had to be confirmed by histology expert central review (NRL). Axitinib was administered orally $5 \mathrm{mg}$ twice daily. Primary endpoint was progression free rate at 24 weeks (24w-PFR) by central review.

Results: Fifty-six patients were screened, and 44 included (13 type 1, 30 type 2, and 1 non-specified). The median follow-up was 32.0 (13.1-39.9] months. The 24w-PFR was $45.2 \%[95 \% \mathrm{Cl} 32.6 \%-+\infty]$, the objective response rate was $28.6 \%(95 \% \mathrm{Cl} 15.7 \%-44.6 \%)$ (type 1: 7.7\%; type 2: 35.7\%). The overall median PFS was $6.6(95 \% \mathrm{Cl} 5.5-9.2)$ months, 6.7 months $[95 \% \mathrm{Cl} 5.5-9.2]$ and 6.2 months $(95 \% \mathrm{Cl} 5.4-9.2)$ for type 1 and 2, respectively. Median overall survival was 18.9 months (95\% $\mathrm{Cl} 12.8$-not reached). Adverse events were as expected, grade 3-4 treatment-related adverse events were rare except hypertension (27\%).

Conclusions: Axitinib demonstrated encouraging efficacy in mPRCC patients, especially in type 2 PRCC. Toxicity was manageable. Axitinib appears as an interesting option for first line treatment and to be worth further investigation in combination with immunotherapy in these patients. Expert pathology review should be recommended in this setting.

Clinical Trial registration: ClinicalTrials.gov, NCT02489695. 


\section{Highlights:}

- No standard treatments exist for metastatic PRCC patients.

- Axitinib showed encouraging results in mPRCC patients, especially in type 2 PRCC, and toxicity was manageable.

- Axitinib appears as an interesting agent to investigate in combination with immunotherapy in mPRCC patients.

- Expert pathology review to confirm PRCC should be recommended. 


\section{Introduction}

Papillary renal cell carcinoma (PRCC) is the second most common subtype of renal carcinoma accounting for approximatively $10-15 \%$ of all renal cancers. Different types of PRCC have been described on the basis of two histologic subtypes, type 1 and type 2, with a worse prognosis reported for type 2 metastatic disease (1). However, molecular analyses recently highlighted the need to refine classification to appropriately integrate newly identified molecular features.(2;3) Gene alterations including MET mutations or amplifications fostered the development of $M E T$-driven therapeutic strategies (4). There is currently no standard of care specifically dedicated to metastatic PRCC (mPRCC) patients (2), and treatments developed for metastatic clear cell carcinomas are commonly used, therefore, mPRCC enrollment in clinical trials is encouraged (5). Clinical trials specifically investigated treatments such as sunitinib, or everolimus approved for advanced clear cell carcinoma, or the dual kinase inhibitor directed both towards VEGF receptors (VEGFr) and the MET pathway foretinib, or more recently, the selective MET inhibitor savolitinib (6-9). Response rates (RR) were disappointing because they were generally below $15 \%$, except in a subset of patients with MET germline alterations (8). Axitinib is indicated as second-line treatment in advanced clear cell carcinoma. Based on its potent VEGFr inhibitory activity, we designed the AXIPAP trial to investigate its inhibitory effect in patients with mPRCC. 


\section{Patients and methods}

\section{Study design}

This multicenter single-arm, phase II trial enrolled patients with locally advanced or metastatic confirmed PRCC in first-line treatment. The study was conducted according to the declaration of Helsinki and the International Conference of Good Clinical Practices after local approval of the Ethic Committee of Lyon Sud-Est IV and all patients provided written informed consent before enrolment. The study was registered on ClinicalTrials.gov, number NCT02489695.

\section{Patients}

Eligible patients had histologically proven advanced or metastatic PRCC (pure type 1, or 2, or mixed, whatever the percentage) confirmed by expert central pathology review. Other inclusion criteria were Eastern Cooperative Oncology Group performance status 0 or 1, age above 18, adequate hematologic, renal and liver functions, at least one measurable lesion by CT-scan as per Response Evaluation Criteria in Solid Tumors (RECIST) version 1.1, no active cardiac disease nor history of grade 3 vascular or cardiac disease, no prior systemic treatment for metastatic renal cancer and no brain metastases.

\section{Treatment and study assessments}

Patients received axitinib (Pfizer, France) orally twice a day until progression or unacceptable toxicity; the starting dose was $5 \mathrm{mg}$ twice daily, with possible dose adaptation according to the label recommendations.

Screening and baseline assessments were performed within 28 days prior axitinib initiation; Radiological response was assessed every 8 to 10 weeks and tumor assessment was classified as partial response (PR), stable disease (SD), or progression by the investigators according to RECIST 1.1 (10). A central radiology review was performed for all patients who received at least 4 weeks of treatment to confirm the progression of the 
disease or not (RECIST 1.1) at 24 weeks or earlier in case of treatment discontinuation. All patients were assessed clinically every 4 weeks, routine blood and urine samples were also verified every 4 weeks. Adverse events were assessed using the Common Terminology Criteria for Adverse Events (CTCAE) version 4.0.

\section{Outcomes}

The primary endpoint was the 24 -week progression-free rate (24w-PFR), defined as the proportion of patients with a complete response $(C R)$, or a partial response $(P R)$, or a stable disease (SD) at 24 weeks according to RECIST 1.1, validated by the central review committee. According to results obtained in two previous trials $(6,7)$, the $24 w$-PFR appeared as an appropriate and rapidly available endpoint.

The secondary endpoints included safety assessed through adverse events grading according to the CTCAE version 4.0, Progression free survival (PFS) in each PRCC subtypes, Overall Survival (OS), Objective Response rate (ORR), and duration of responses.

\section{Statistics and data analysis}

We calculated the sample size using A'Hern's single-stage design for phase II trials with the assumption that axitinib should result in a non-progression rate at 24 weeks (24wPFR) of at least $45 \%$ to be judged appropriate for further investigation. This threshold used the $24 \mathrm{w}$-PFR of $45 \%$ observed in type 1 and 2 PRCC patients treated by sunitinib in the SUPAP first-line study (6). A $65 \%$ cut-off was defined as the expected minimum efficacy threshold in our study, close to $57 \%$ defined as the upper bound of the $95 \% \mathrm{Cl}$ for $24 \mathrm{~W}$-PFR reported in former trials. A sample size of 42 patients provided $80 \%$ power to reject the null hypothesis with a one-sided, type 1 error of 5\%, 25 patients being the lower cutoff point of decision making. To account for a non-assessable patient rate of $15 \%$, eight patients were added to reach a total sample size of 50 patients. 
The primary endpoint was assessed in terms of success and failure, with success defined as being progression free at 24 weeks, and failure defined as disease progression, or death from any cause within the 24 weeks following treatment initiation, or axitinib permanent discontinuation for toxicity before 24 weeks. The 24-week progression free rate is presented as a proportion with its unilateral 95\% confidence interval $(\mathrm{Cl})$.

Progression free survival (PFS) was defined as the time from axitinib initiation to the date of first documented event of disease progression according to RECIST version 1.1 or death from any cause, whichever occurred first. Patients with no event at the time of analysis were censored at the date of last adequate tumour assessment. Overall survival (OS) was defined as the time from axitinib initiation until death from any cause. Patients alive at the time of analysis were censored at the date of last contact.

PFS and OS were estimated using the Kaplan-Meier method, and described in terms of median survival, along with the associated 2 -sided $95 \% \mathrm{Cls}$ for the estimates. PFS distributions were compared between the two PRCC subtypes using the Log-Rank test. Median follow-up (min-max) was calculated by a reverse Kaplan-Meier estimate. Qualitative variables are described using frequency and percentage. Quantitative data are described using median, minimum and maximum values. All analyses were done with SAS (version 9.4).

Data cut-off was May 6, 2019 for the final analysis.

Review of the literature: Medline database was searched using the following keywords: advanced or metastatic papillary renal carcinoma or non-clear cell renal carcinoma and treatment and trial. We exclusively considered prospective trials with at least 12 patients with papillary carcinoma. 


\section{Results}

\section{Patients}

Between October 2015 and January 2018, 56 patients from 7 centers were screened for eligibility (Table S1). Histologic pathology central review was performed and confirmed PRCC diagnosis in 44 patients; five patients had other renal carcinoma subtypes. Seven patients did not meet other inclusion/exclusion criteria (Figure 1). Table 1 shows patient demographics and baseline characteristics.

\begin{tabular}{|c|c|}
\hline Characteristic & $\begin{array}{l}\text { Patients with confirmed PRCC } \\
\qquad(\mathrm{N}=44)\end{array}$ \\
\hline Median age at inclusion (years) & $65.0(27.5-82.7)$ \\
\hline \multicolumn{2}{|l|}{ ECOG performance status } \\
\hline 0 & $22(50.0 \%)$ \\
\hline 1 & $22(50.0 \%)$ \\
\hline \multicolumn{2}{|l|}{ Gender } \\
\hline Male & $37(84.1 \%)$ \\
\hline Female & $7(15.9 \%)$ \\
\hline \multicolumn{2}{|l|}{ PRCC type } \\
\hline Type 1 & $13(30.2 \%)$ \\
\hline Type 2 & $30(69.8 \%)$ \\
\hline Not specified & 1 \\
\hline \multicolumn{2}{|l|}{ Disease status at diagnosis } \\
\hline Synchonous metastases & $19(43.2 \%)$ \\
\hline Metachronous metastases & $25(56.8 \%)$ \\
\hline \multicolumn{2}{|c|}{ Number of metastatic sites at inclusion } \\
\hline 1 & $4(16.0 \%)$ \\
\hline 2 & $12(48.0 \%)$ \\
\hline Greater than 2 sites & $9(36.0 \%)$ \\
\hline \multicolumn{2}{|l|}{ Previous treatment } \\
\hline Nephrectomy & $37(84.1 \%)$ \\
\hline Metastasectomy & $6(13.6 \%)$ \\
\hline Radiotherapy & 7 (15.9\%) \\
\hline Other & 7 (15.9\%) \\
\hline \multicolumn{2}{|l|}{ MSKCC risk score (11) } \\
\hline Favourable & $9(23.1 \%)$ \\
\hline Intermediate & $24(61.5 \%)$ \\
\hline High & $6(15.4 \%)$ \\
\hline Missing data & 5 \\
\hline \multicolumn{2}{|l|}{ IMDC score $(12 ; 13)$} \\
\hline Favourable & $10(23.8 \%)$ \\
\hline Intermediate & $19(45.2 \%)$ \\
\hline High & $13(31.0 \%)$ \\
\hline
\end{tabular}


Table 1. Patient demographics and baseline characteristics. Data are median (range) or $n$ (\%) unless otherwise indicated. ECOG=Eastern Cooperative Oncology Group.

The majority $(N=30,69.8 \%)$ of patients had type 2 PRCC. Most patients underwent a prior nephrectomy $(N=37,84 \%)$ and were classified in the intermediate or poor prognosis groups according to the Memorial Sloan Kettering Cancer Center (MSKCC) score $(N=30$, 76.9\%) or International Metastatic RCC Database Consortium (IMDC) score ( $N=32,76.2 \%)$.

\section{Treatment exposure}

At the time of the analysis, the median follow-up was 32.0 (13.1-39.9) months and 4 patients were still on treatment (total administration duration from 14 to 22 months). The average daily dose of axitinib was $10 \mathrm{mg}$. The median duration of exposure to axitinib was $8.0(0.3-31.3)$ months, $36(81.8 \%)$ patients had at least one dose modification for toxicity including 7 (15.9\%) patients who prematurely discontinued treatment due to adverse events (transient ischemic attacks $(n=1)$; myocardial infarction $(n=1)$; acute renal insufficiency $(n=1)$; masticatory muscles cramps $(n=1)$, peritonitis and septic shock $(n=1)$, peritoneal bleeding $(n=1)$, general physical deterioration $(n=1))$. The daily dose was adapted according to manufacturer recommendations and 21 (48\%) patients received more than $10 \mathrm{mg}$ axitinib, including 14 (32\%) patients who received more than $14 \mathrm{mg}$ per day.

25 of 36 patients discontinued treatment before 18 months and initiated another treatment: nivolumab $(n=8)$, cabozantinib $(n=8)$, everolimus $(n=5)$, sunitinib $(n=3)$ and temsirolimus $(n=1)$.

Efficacy 
The 24 w-PFR was $45.2 \%(95 \% \mathrm{Cl} 32.6 \%$ to $+\infty)$ in 42 evaluable patients according to the review committee, $46.2(95 \% \mathrm{Cl} 23.4$ to $+\infty)$ in type I and $42.9(95 \% \mathrm{Cl} 27.5$ to $+\infty)$ in type 2. The objective response rate (ORR) assessed by the investigators was $28.6 \%(95 \% \mathrm{Cl}$ 15.7-44.6) in the global population, and $7.7 \%$ and $35.7 \%$ in type 1 and 2 , respectively (Table 2). The median duration of response in the 12 patients who have achieved PR was 7.9 months (3.7-18.3), and reached $15.7(13.0-18.3)$ in the 2 patients with favorable risk according to IMDC risk criteria (13). Figure 2 shows the change in tumor measurements in both subtypes.

\begin{tabular}{lccc}
\hline & $\begin{array}{c}\text { Global PRCC } \\
\text { population }(N=42)^{ \pm}\end{array}$ & $\begin{array}{c}\text { Type 1 subgroup } \\
(N=13)\end{array}$ & $\begin{array}{c}\text { Type 2 subgroup } \\
(N=28)^{*}\end{array}$ \\
\hline Best response & & & $1(7.7 \%)$ \\
PR $^{ \pm}$ & $12(28.6 \%)^{ \pm}$ & $10(76.9 \%)$ & $10(35.7 \%)$ \\
SD & $26(61.9 \%)$ & $2(15.4 \%)$ & $16(57.1 \%)$ \\
PD & $4(9.5 \%)$ & 6.7 & $2(7.1 \%)$ \\
Median PFS (months) & 6.6 & $(95 \% \mathrm{Cl} 2.9-14.0)$ & $(95 \% \mathrm{Cl} 5.4-9.2)$ \\
& $(95 \% \mathrm{Cl} 5.5-9.2)$ & 46.2 & 42.9 \\
24w-PFR & 45.2 & $(95 \% \mathrm{Cl} 23.4-+\infty)$ & $(95 \% \mathrm{Cl} 27.5-+\infty)$ \\
Median OS (months) & $(95 \% \mathrm{Cl} 32.6-+\infty)$ & $\mathrm{NR}$ & 17.4 \\
& 18.9 & & $(95 \% \mathrm{Cl} 11.4-\mathrm{NR})$ \\
\hline
\end{tabular}

Table 2. Efficacy endpoints in the global PRCC population, and type 1 or type 2 subgroups. ${ }^{ \pm}$To note, the type subgroup was not specified for one patient in PR. *2 patients in the type 2 subgroup received less than 4 weeks treatment duration and were subsequently excluded from the efficacy analysis. Data are $n$ (\%). Best responses were investigator-assessed. PR: Partial response; SD: stable disease; PD: progression disease. PFS: Progression free survival. 24w-PFR: centrally-assessed progression free rate at 24 weeks. OS: Overall survival. ${ }^{ \pm}$ Subgroup type was not specified for one patient. NR: Not reached.

The median PFS was 6.6 months $(95 \% \mathrm{Cl} 5.5-9.2)$ in the whole population. The median PFS according to the papillary subtypes (Figure 3) was 6.7 months (95\% $\mathrm{Cl} 2.9-14.0)$ and 6.2 months (95\% Cl 5.4-9.2) for type 1 and 2, respectively. At the time of the analysis, 23 patients have died with median overall survival (OS) of 18.9 (95\% Cl 12.8-not reached) months, not yet reached in type 1, and 17.4 months (11.4-not reached) in type 2 papillary 
carcinoma. There was no difference in response rate or PFS according to the dose delivered.

Safety

Adverse events were as expected and are detailed in Table 3.

\begin{tabular}{lcc}
\hline Treatment-related adverse events & All grade & Grade 3 or 4 \\
\hline Fatigue & $34(77.3 \%)$ & $2(4.5 \%)$ \\
Hypertension & $28(63.6 \%)$ & $12(27.3 \%)$ \\
Dysphonia & $26(59.1 \%)$ & $0(0.0 \%)$ \\
Diarrhea & $25(56.8 \%)$ & $3(6.8 \%)$ \\
Anorexia & $16(36.4 \%)$ & $3(7 \%)$ \\
Nausea & $17(38.6 \%)$ & $0(0.0 \%)$ \\
Loss Weight & $11(25.0 \%)$ & $1(2.3 \%)$ \\
Stomatitis & $12(27.3 \%)$ & $0(0.0 \%)$ \\
Vomiting & $8(18.2 \%)$ & $0(0.0 \%)$ \\
Constipation & $8(18.2 \%)$ & $0(0.0 \%)$ \\
Hand \& Foot & $15(34.1 \%)$ & $1(2.3 \%)$ \\
Hypothyroidism & $9(20.5 \%)$ & $0(0.0 \%)$ \\
Abdominal pain & $6(13.6 \%)$ & $1(2.3 \%)$ \\
Mucosal inflammation & $5(11.4 \%)$ & $1(2.3 \%)$ \\
Pruritus & $5(11.4 \%)$ & $0(0.0 \%)$ \\
\hline
\end{tabular}

Table 3. Treatment-related adverse events in the safety population $(N=44)$.

Treatment-related adverse events of any grade that occurred during the treatment in at least $10 \%$ of patients, or treatment-related adverse events of grade 3 or 4 that occurred during the treatment in at least $5 \%$ of patients. Data are $n(\%)$.

$43(97.7 \%)$ out of the 44 patients analysed in the safety population experienced at least one treatment-related adverse event including 24 (54.5\%) patients with at least one grade $\geq 3$ treatment-related adverse event and grade $\geq 3$ hypertension represents half of the cases. No toxic death occurred. Side effects were those generally observed with axitinib. Most common AEs were related to vascular effects, that is, hypertension, dysphonia, and diarrhea. 


\section{Discussion}

The AXIPAP trial is the first prospective trial reporting the use of axitinib in previously untreated mPRCC. Classification of this rare histologic subtype of renal carcinoma is difficult to achieve. Misclassification rate exceeds $9 \%$ in the present trial. The centralised pathology review of the international trial RAPTOR investigating the use of everolimus in this subpopulation reported a re-classification rate of $21.7 \%$.(7) Therefore, a central pathology review should be mandatory in all future trials investigating papillary renal carcinomas.

Patients with mPRCC receiving axitinib in the AXIPAP trial achieved a 24-week PFR (24wPFR) of $45.2 \%$. The trial showed 19 non progressive patients at 24 weeks according to central review assessment. Nevertheless, median PFS was 6.6 months, median OS 18.9 months and, interestingly, the objective response rate was $28.6 \%$. Results from different clinical trials in patients with MPRCC vary according to the population and selection methods used, and especially the use of pathology central review or not, to confirm PRCC. In our trial, patients had PRCC confirmed with histology central review. The magnitude of disease control rate achieved with axitinib is similar to that reached in naïve patients with sunitinib in a specific phase 2 trial, or in stratified subgroup analyses of randomised trials enrolling different non clear cell renal carcinomas (Table 4).

\begin{tabular}{|c|c|c|c|c|c|}
\hline & $\begin{array}{l}\text { Targeted therapy } \\
\text { (trial name) }\end{array}$ & $\begin{array}{l}\text { Patients } \\
\text { (N) }\end{array}$ & $\begin{array}{l}\text { Response } \\
\text { Rate }\end{array}$ & $\begin{array}{l}\text { Median } \\
\text { PFS } \\
\text { (Months) }\end{array}$ & $\begin{array}{l}\text { Median OS } \\
\text { (Months) }\end{array}$ \\
\hline \multicolumn{6}{|l|}{ VEGFR TKI } \\
\hline \multirow[t]{3}{*}{ VEGFR TKI } & Axitinib (AXIPAP) & 44 & $28.6 \%$ & 6.6 & 18.9 \\
\hline & & & & 6.7 type 1 & NR type 1 \\
\hline & & & & 6.2 type 2 & 17.4 type 2 \\
\hline \multirow[t]{2}{*}{ VEGFR TKI } & Sunitinib (SUPAP) (6) & 15 type 1 & $12 \%$ & 6.6 type 1 & 17.8 type 1 \\
\hline & & 46 type 2 & & 5.5 type 2 & 12.4 type 2 \\
\hline VEGFR TKI & Sunitinib $(14)^{a}$ & 22 type 1 & $23.5 \%$ & 6.4 & NR \\
\hline VEGFR TKI & Sunitinib (15) ${ }^{\mathrm{b}}$ & 27 type 2 & $0 \%$ & 1.6 & 12.6 \\
\hline EGFR TKI & & & & & \\
\hline
\end{tabular}




\begin{tabular}{|c|c|c|c|c|c|}
\hline EGFR TKI & Erlotinib (16) & 45 & $11 \%$ & NR & NR \\
\hline \multicolumn{6}{|l|}{ mTOR Inhibition } \\
\hline \multirow{2}{*}{ mTOR Inhibition } & Everolimus (RAPTOR) (7) & 23 type 1 & $1 \%$ & 5 type 1 & 17.8 type 1 \\
\hline & & 46 type 2 & & 4 type 2 & 20.5 type 2 \\
\hline \multicolumn{6}{|l|}{$\begin{array}{l}\text { VEGFR mTOR Combined } \\
\text { therapy }\end{array}$} \\
\hline \multicolumn{6}{|l|}{ mTOR Inhibition } \\
\hline $\begin{array}{l}\text { VEGFR TKI vs } \\
\text { mTOR Inhibition }\end{array}$ & Sunitinib vs Everolimus (ESPN) (18) & 51 vs 57 & $7 \%-0 \%$ & $5.7-4.1$ & $16.6-14.9$ \\
\hline \multicolumn{6}{|l|}{ cMET Inhibition } \\
\hline \multirow[t]{2}{*}{ cMET Inhibition } & Savolitinib & $109^{c}$ & $7 \%$ & 1.4 & NR \\
\hline & In MET driven tumors (9) & 44 & $18 \%$ & 6.2 & \\
\hline cMET Inhibition and VEGFR & Foretinib & $74^{d}$ & $13.5 \%$ & 9.3 & NR \\
\hline Inhibition & in MET germline mutation (8) & 10 & $50 \%$ & & \\
\hline $\begin{array}{l}\text { cMET Inhibition vs } \\
\text { cMET \& EGFR Inhibition }\end{array}$ & $\begin{array}{l}\text { Tivantinib vs Tivantinib \& Erlotinib (19) } \\
\text { e }\end{array}$ & 25 vs 25 & $0 \%-0 \%$ & 2-3.9 & $10-11.3$ \\
\hline cMET kinase activity Inhibition & Crizotinib (CREATE) (20) & $23 * * *$ & $17 \%$ & NR & NR \\
\hline \multicolumn{6}{|l|}{$\begin{array}{l}\text { Immune checkpoint } \\
\text { inhibition }\end{array}$} \\
\hline Anti-PD1 Ab & Pembrolizumab (21) & 118 & $25.4 \%$ at $12 w$ & 4.1\# & $72 \%$ at 1 year\# \\
\hline Anti-PDL1 $A b+$ anti VEGF $A b$ & Atezolizumab+Bevacizumab (22) ${ }^{f}$ & 12 & $25 \%$ & NR\#\# & NR\#\# \\
\hline Inhibition cMET and PDL-1 & Savolitinib+Durvalumab (CALYPSO) $(23)^{\mathrm{g}}$ & 41 & $27 \%$ & NR & 6.9 (immature) \\
\hline
\end{tabular}

Table 4 - Response rate (RR), median progression free survival (PFS) and median overall survival (OS) of targeted therapies or immunotherapy in mPRCC patients. NR: Not reached; Ab: Antibody (monoclonal antibody). Patients (\%) who had received previous therapy(ies) ${ }^{a} 36 \%$; ${ }^{b} 14 \%$ (less than 2 previous treatments); ${ }^{\mathrm{c}} 45 \%$ (up to $\geq 3$ previous treatment); ${ }^{\mathrm{d}} 19 \%{ }^{\mathrm{e}}{ }^{\mathrm{e}} 34 \% ;{ }^{\mathrm{f}} 48 \%{ }^{\mathrm{g}} 32 \%$; ${ }^{* * *} \mathrm{mPRCC}$ type 1 -eligible and evaluable patients only; ++ Median OS obtained in all non-clear cell carcinomas; \# in the global population of 165 patients including 118 (71\%) patients with mPRCC; \#\# in the global population of 65 patients including $12 \mathrm{mPRCC}$.

PFS and OS appeared shorter in the phase 2 trial investigating axitinib after failure of first line temsirolimus treatment, that is, 3.5 and 8.3 months, respectively; however no central review for pathology or radiology had been performed in this trial (24).

This study has some limitations. The overall response rate was exclusively based on investigator assessment; correlative genomic studies such as MET status determination are lacking and deserve to be further explored.

The AXIPAP trial showed 24w-PFR based on central review assessment to be slightly more favourable and overall survival is longer in type 1 compared with type 2 subgroup. Longer 
survivals were previously reported in type $1 \mathrm{mPRCC}$ patients potentially reflecting a rather slow tumor growth $(1 ; 3 ; 6)$. Notably, all but one responders in the AXIPAP trial had a type 2 mPRCC. Trials investigating different VEGFr inhibitors reported higher response rates in type 2 than in type $1 \mathrm{mPRCC}$ patients $(6 ; 24)$. These results indicate that type 2 papillary renal carcinoma, regardless of their recently demonstrated molecular heterogeneity, seems to be more dependent on the VEGF pathway than the type 1 subgroup $(1 ; 3 ; 25)$.

MET alterations have been quite often reported especially in the type 1 subgroup (1-4). Therapies targeting the MET pathway were thus developed with some degrees of efficacy especially in patients with MET germline mutations $(8 ; 9 ; 20)$. However, recent results in patients with tumors harboring non-germline MET alterations did not support the development of savolitinib, a MET-directed agent alone in phase 3 trials (9). The randomized phase 2 trial PAPMET (NCT02761057) investigates the efficacy of cabozantinib which seems to have some activity in retrospectives series of $\operatorname{mRCC}(26 ; 27)$. As previously reported in clear cell renal carcinoma, the tumor heterogeneity in papillary renal carcinoma has to be considered. Some tumors may mostly depend on the VEGF pathway while others may be driven by other genes or pathways $(3 ; 25 ; 28)$. Preliminary results from prospective trials using immune check point inhibitors such as PD1 or PDL1 directed antibodies in $\mathrm{MPRCC}$ recently reported interesting response rates, although confirmation of efficacy is still expected (21-23).

Axitinib combined with PD1- or PDL1-directed antibodies showed efficacy with manageable toxicity in patients with metastatic clear cell carcinoma and is now registered for use in the USA. This combination should be further investigated in patients with $\operatorname{mPRCC}(29 ; 30)$.

\section{Conclusions}


Expert pathology review to confirm PRCC should be recommended. Axitinib showed encouraging results in mPRCC patients, especially in type 2 PRCC, and toxicity was manageable. Axitinib appears as an interesting agent to investigate in combination with immunotherapy in $\mathrm{mPRCC}$ patients. 


\section{Acknowledgements}

The trial was supported by Pfizer.

We thank the participating patients, staff at each of the study sites. Special thanks to $\mathrm{Dr}$ A. Guyennon and $\operatorname{Dr}$ A Basle for their participation as member of central pathology review board, and Sophie Darnis, PhD, (Centre Léon Bérard) for medical editorial assistance with this report.

\section{Funding: Pfizer, Centre Léon Bérard}

The funder of the study, Centre Leon Berard, was responsible for trial conception and coordination, data analysis, and writing of the report. All authors were involved in writing and reviewing the report and in making the decision to submit for publication. SN, EB, CSF, and DP had full access to all study data and full responsibility to submit for publication. Pfizer provided the study drug axitinib and funding to Centre Leon Berard to conduct the study. Pfizer had no role in study design, data collection, data analysis, data interpretation, or writing of the report.

\section{Disclosure of potential conflicts of interest:}

Dr. Negrier reports grants, personal fees, non-financial support and other from PFIZER, grants, personal fees and other from IPSEN, during the conduct of the study; personal fees and other from BMS, personal fees from EUSAPHARMA, personal fees from NOVARTIS, personal fees from MSD, outside the submitted work; Dr. Rioux-Leclercq reports personal fees from PFIZER and BMS, outside the submitted work; for conferences on non-clear cell RCC and molecular pathways in RCC. Dr. Gross-Goupil reports personal fees and non-financial support from IPSEN, personal fees and nonfinancial support from ROCHE, personal fees and non-financial support from MSD, 
personal fees and non-financial support from BMS, personal fees and non-financial support from PFIZER, non-financial support from NOVARTIS, outside the submitted work; .; Dr. Gravis reports non-financial support from PFIZER, non-financial support from BMS, non-financial support from IPSEN during the conduct of the study; Dr. Chevreau reports personal fees from PFIZER, personal fees and non-financial support from BMS, personal fees and non-financial support from IPSEN, personal fees and non-financial support from ASTRAZENECA, personal fees and non-financial support from MSD, personal fees from null, during the conduct of the study; grants from PFIZER, outside the submitted work; Dr. Boyle reports grants and non-financial support from PFIZER, during the conduct of the study; non-financial support from PFIZER, non-financial support from BMS, personal fees and non-financial support from IPSEN, personal fees from SANOFI, non-financial support from ASTELLAS, non-financial support from JANSEN, outside the submitted work; Dr. Rolland reports personal fees from PFIZER, personal fees from BMS, personal fees from IPSEN, outside the submitted work; personal fees from NOVARTIS, personal fees from BMS, personal fees and non-financial support from MSD, personal fees and non-financial support from IPSEN, outside the submitted work; Dr. Ravaud reports personal fees and non-financial support from PFIZER, personal fees and non-financial support from BMS, personal fees and non-financial support from Roche, personal fees and non-financial support from IPSEN, personal fees and nonfinancial support from ASTRAZENECA, personal fees and non-financial support from MSD, from null, during the conduct of the study; grants from PFIZER outside the submitted work; Dr. Flechon reports honorarium and travel expenses from PFIZER, honorarium and travel expenses from NOVARTIS, honorarium and travel expenses from IPSEN, honorarium and travel expenses from BMS, outside the submitted work; Dr. Albiges reports other from PFIZER, other from NOVARTIS, other from BMS, other from 
IPSEN, other from ROCHE, other from MSD, other from ASTRAZENECA, outside the submitted work; Dr. Pérol reports personal fees and non-financial support from ROCHE, personal fees and non-financial support from ASTRAZENECA, grants from MSD AVENIR, outside the submitted work. Dr. Escudier reports grants and personal fees from PFIZER, during the conduct of the study; grants and personal fees from BMS, ROCHE, AVEO, NOVARTIS, IPSEN, outside the submitted work; Dr. Dermeche, Dr. Geoffrois, Mrs Blanc, and Mrs Ferlay declare no competing interests. 


\section{Figure legends}

Figure 1. Trial profile. ${ }^{* * 2}$ patients with type 2 PRCC received less than 4 weeks treatment duration and were subsequently excluded for the efficacy analysis $(N=42)$.

Figure 2. Maximum change from baseline in target lesions. One patient clinically progressive according to the investigator had no lesion measurement.

Figure 3. Progression-free survival (PFS) A) in the global population, B) according to histological subtypes of PRCC. Kaplan-Meier plots for progression-free survival. Data cutoff was May 6, 2019. 


\section{Reference List}

(1) Connor WJ, Donskov F, Fraccon AP, Pasini F, Bjarnason GA, Beuselinck B, et al. Characterizing the outcomes of metastatic papillary renal cell carcinoma. Cancer Med 2017 May;6(5):902-9.

(2) Linehan WM, Spellman PT, Ricketts CJ, Creighton CJ, Fei SS, Davis C, et al. Comprehensive Molecular Characterization of Papillary Renal-Cell Carcinoma. N Engl J Med 2016 Jan 14;374(2):135-45.

(3) Ricketts CJ, De Cubas AA, Fan H, Smith CC, Lang M, Reznik E, et al. The Cancer Genome Atlas Comprehensive Molecular Characterization of Renal Cell Carcinoma. Cell Rep 2018 Apr 3;23(1):313-26.

(4) Albiges L, Guegan J, LeFormal A., Verkarre V, Rioux-Leclercq N, Sibony M, et al. MET is a potential target across all papillary renal cell carcinomas: result from a large molecular study of pRCC with CGH array and matching gene expression array. Clin Cancer Res 2014 Jul 1;20(13):3411-21.

(5) Escudier B, Porta C, Schmidinger M, Rioux-Leclercq N, Bex A, Khoo V, et al. Renal cell carcinoma: ESMO Clinical Practice Guidelines for diagnosis, treatment and follow-up. Ann Oncol 2019 May 1;30(5):706-20.

(6) Ravaud A, Oudard S, De FM, Chevreau C, Gravis G, Zanetta S, et al. First-line treatment with sunitinib for type 1 and type 2 locally advanced or metastatic papillary renal cell carcinoma: a phase II study (SUPAP) by the French Genitourinary Group (GETUG). Ann Oncol 2015 Jun;26(6):1123-8.

(7) Escudier B, Molinie V, Bracarda S, Maroto P, Szczylik C, Nathan P, et al. Open-label phase 2 trial of first-line everolimus monotherapy in patients with papillary metastatic renal cell carcinoma: RAPTOR final analysis. Eur J Cancer 2016 Dec;69:226-35.

(8) Choueiri TK, Vaishampayan U, Rosenberg JE, Logan TF, Harzstark AL, Bukowski RM, et al. Phase II and biomarker study of the dual MET/VEGFR2 inhibitor foretinib in patients with papillary renal cell carcinoma. J Clin Oncol 2013 Jan 10;31(2):181-6.

(9) Choueiri TK, Plimack E, Arkenau HT, Jonasch E, Heng DYC, Powles T, et al. Biomarker-Based Phase II Trial of Savolitinib in Patients With Advanced Papillary Renal Cell Cancer. J Clin Oncol 2017 Sep 10;35(26):2993-3001.

(10) Eisenhauer EA, Therasse P, Bogaerts J, Schwartz LH, Sargent D, Ford R, et al. New response evaluation criteria in solid tumours: revised RECIST guideline (version 1.1). Eur J Cancer 2009 Jan;45(2):228-47.

(11) Motzer RJ, Bacik J, Schwartz LH, Reuter V, Russo P, Marion S, et al. Prognostic factors for survival in previously treated patients with metastatic renal cell carcinoma. J Clin Oncol 2004 Feb 1;22(3):454-63. 
(12) Heng DY, Xie W, Regan MM, Warren MA, Golshayan AR, Sahi C, et al. Prognostic factors for overall survival in patients with metastatic renal cell carcinoma treated with vascular endothelial growth factor-targeted agents: results from a large, multicenter study. J Clin Oncol 2009 Dec 1;27(34):5794-9.

(13) Heng DY, Xie W, Regan MM, Harshman LC, Bjarnason GA, Vaishampayan UN, et al. External validation and comparison with other models of the International Metastatic Renal-Cell Carcinoma Database Consortium prognostic model: a population-based study. Lancet Oncol 2013 Feb;14(2):141-8.

(14) Lee JL, Ahn JH, Lim HY, Park SH, Lee SH, Kim TM, et al. Multicenter phase II study of sunitinib in patients with non-clear cell renal cell carcinoma. Ann Oncol 2012 Aug;23(8):2108-14.

(15) Tannir NM, Plimack E, Ng C, Tamboli P, Bekele NB, Xiao L, et al. A phase 2 trial of sunitinib in patients with advanced non-clear cell renal cell carcinoma. Eur Urol 2012 Dec;62(6):1013-9.

(16) Gordon MS, Hussey M, Nagle RB, Lara PN, Jr., Mack PC, Dutcher J, et al. Phase II study of erlotinib in patients with locally advanced or metastatic papillary histology renal cell cancer: SWOG S0317. J Clin Oncol 2009 Dec 1;27(34):5788-93.

(17) Armstrong AJ, Halabi S, Eisen T, Broderick S, Stadler WM, Jones RJ, et al. Everolimus versus sunitinib for patients with metastatic non-clear cell renal cell carcinoma (ASPEN): a multicentre, open-label, randomised phase 2 trial. Lancet Oncol 2016 Mar;17(3):378-88.

(18) Tannir NM, Jonasch E, Albiges L, Altinmakas E, Ng CS, Matin SF, et al. Everolimus Versus Sunitinib Prospective Evaluation in Metastatic Non-Clear Cell Renal Cell Carcinoma (ESPN): A Randomized Multicenter Phase 2 Trial. Eur Urol 2016 May;69(5):866-74.

(19) Twardowski PW, Tangen CM, Wu X, Plets MR, Plimack ER, Agarwal N, et al. Parallel (Randomized) Phase II Evaluation of Tivantinib (ARQ197) and Tivantinib in Combination with Erlotinib in Papillary Renal Cell Carcinoma: SWOG S1107. Kidney Cancer 2017 Nov 27;1(2):123-32.

(20) Schoffski P, Wozniak A, Escudier B, Rutkowski P, Anthoney A, Bauer S, et al. Crizotinib achieves long-lasting disease control in advanced papillary renal-cell carcinoma type 1 patients with MET mutations or amplification. EORTC 90101 CREATE trial. Eur J Cancer 2017 Dec;87:147-63.

(21) Suarez C., Lee J-L., Ziobro M., Gafanov R.A., Matveev V.B., Donskov F. et al First-line pembrolizumab (pembro) monotherapy for advanced non-clear cell renal cell carcinoma (nccRCC): Updated follow-up for KEYNOTE-427 cohort B. Ann Oncol 2019 Oct; 30 (suppl 5):v381, abstr \#948P. doi:10.1093/annonc/mdz249.

(22) McKay R.R., McGregor B.A., Braun D.A., Werner L., Gray K., Flaifel A., et al. Results of a Multicenter Phase II Study of Atezolizumab and Bevacizumab for Patients With Metastatic Renal Cell Carcinoma With Variant Histology and/or Sarcomatoid Features. J Clin Oncol 2020 Jan 1;38(1):63-70. 
(23) Suarez-Rodriguez C., Larkin J., Patel P., Perez-Valderrama B., Rodriguez-Vida A., Glen H., Overall survival results of durvalumab and savolitinib in metastatic papillary renal cancer (CALYPSO) J Clin Oncol 2020, 38, Suppl 6, abstr \#619.

(24) Park I, Lee SH, Lee JL. A Multicenter Phase II Trial of Axitinib in Patients With Recurrent or Metastatic Non-clear-cell Renal Cell Carcinoma Who Had Failed Prior Treatment With Temsirolimus. Clin Genitourin Cancer 2018 Oct;16(5):e997-e1002.

(25) Saleeb RM, Brimo F, Farag M, Rompre-Brodeur A, Rotondo F, Beharry V, et al. Toward Biological Subtyping of Papillary Renal Cell Carcinoma With Clinical Implications Through Histologic, Immunohistochemical, and Molecular Analysis. Am J Surg Pathol 2017 Dec;41(12):1618-29.

(26) Campbell MT, Bilen MA, Shah AY, Lemke E, Jonasch E, Venkatesan AM, et al. Cabozantinib for the treatment of patients with metastatic non-clear cell renal cell carcinoma: $A$ retrospective analysis. Eur J Cancer 2018 Nov;104:188-94.

(27) Martinez CN, Xie W, Asim BM, Dzimitrowicz H, Burkart J, Geynisman DM, et al. Cabozantinib in advanced non-clear-cell renal cell carcinoma: a multicentre, retrospective, cohort study. Lancet Oncol 2019 Apr;20(4):581-90.

(28) McDermott D.F., Huseni M.A., Atkins M.B., Motzer R.J., Rini B.I., Escudier B., et al Clinical activity and molecular correlates of response to atezolizumab alone or in combination with bevacizumab versus sunitinib in renal cell carcinoma. Nat Med 2018Jun;24(6):749-757.

(29) Rini Bl, Plimack ER, Stus V, Gafanov R, Hawkins R, Nosov D, et al. Pembrolizumab plus Axitinib versus Sunitinib for Advanced Renal-Cell Carcinoma. N Engl J Med 2019 Mar 21;380(12):1116-27.

(30) Motzer RJ, Penkov K, Haanen J, Rini B, Albiges L, Campbell MT, et al. Avelumab plus Axitinib versus Sunitinib for Advanced Renal-Cell Carcinoma. N Engl J Med 2019 Mar 21;380(12):1103-15. 